\title{
Ozone Therapy in a Patient with Diabetic Foot Ulcerations and a Decision for Amputation*
}

\author{
Saltuk Aytacoglu1, Barlas Naim Aytacoglu2\# \\ ${ }^{1}$ Vocational School of Health, Girne American University, Girne, TRNC \\ ${ }^{2}$ Faculty of Medicine, Girne American University, Girne, TRNC \\ Email: "baytacoglu@yahoo.com
}

How to cite this paper: Aytacoglu, S. and Aytacoglu, B.N. (2019) Ozone Therapy in a Patient with Diabetic Foot Ulcerations and a Decision for Amputation. Case Reports in Clinical Medicine, 8, 35-41. https://doi.org/10.4236/crcm.2019.82005

Received: January 7, 2019

Accepted: January 28, 2019

Published: January 31, 2019

Copyright () 2019 by author(s) and Scientific Research Publishing Inc. This work is licensed under the Creative Commons Attribution International License (CC BY 4.0).

http://creativecommons.org/licenses/by/4.0/

(c) (i) Open Access

\begin{abstract}
Background: Diabetic foot together with open wounds in distal type peripheral arterial disease constitutes a challenge in therapeutic planning. Ozone therapy may unveil new horizons in management. Case Report: A 67-year-old woman with diabetes mellitus was applied with open wounds at the bottom of her foot with purulent discharge, with a decision for above ankle amputation. She had had numerous interventions for her wounds including metatarsal amputations due to osteomyelitis and had been on an intense treatment including antibiotics, insulin, antihypertensives and antiaggregants. Angiogram revealed diffuse peripheral arterial disease in lower extremities. All medication but antihypertensives was stopped. She received major medical ozone application as 2000 gamma/session i.v. for 2 weeks, external ozone sac application starting from 60 and dropping to 30 gamma/session for 3 weeks and ozone insuflation 40 gamma/session for 10 sessions. Her purulent discharge ceased after the third session and the atonic debris of the wounds exfoliated, the wounds healed from the base towards the surface of the skin. She was then put on cilostazol and clopidogrel therapy. Conclusion: By being one of the known strongest bactericide, virucide, and fungicide elements, medical ozone therapy stimulates and upregulates the antioxidant system of the body with its hormesis effects. After the cessation of all circulatory system supporting medication (as their interaction with ozone is not clear yet), appropriate ozone therapy may bring new horizons for patients when all classically known methods of treatment have been completed, before assigning the patients for amputation.
\end{abstract}

\section{Keywords}

Diabetic Foot Ulceration, Medical Ozone Treatment, Diabetes Mellitus, Extremity Amputation

"This case was presented as a Poster Presentation (PP 158) in the joined 18th National Vascular and Endovascular Congress and 9th National Phlebology Congress in Girne, Elexus Hotel, TRNC, held between 9 and 12 November, 2017. 


\section{Introduction}

The prevalence of diabetes mellitus (DM) was reported to be $2.8 \%$ in 2000 and was projected to be around $4.4 \%$ in 2030 . This increase has been attributed to the growth of the population, aging of the population, urbanization, increase in the number of the obese people, increase of metabolic syndrome parameters and increase in physical inactivity [1] [2]. It is without any doubt that complications related with DM will also be increasing in the coming future parallel to its prevalence as studies put forward [3]. 1 in four DM patients are reported to develop diabetic foot ulceration (DFU) [4].

The pooled global DFU, a major and disabling complication of DM which may end up with amputations of the affected extremity/extremities, is found to be $6.3 \%$, with highest prevalence in the USA (13.0\%) and lowest in Oceania (3.0\%) [3].

Many different methods and combination therapies are being carried out in an effort to eradicate this disabling clinical entity; however, it still constitutes and is expected to constitute a major problem as a complication of DM.

The objective of this case report is to put forward a different approach in terms of complementary medicinal applications (which may sometimes be used as a primary medical application), namely, ozone therapy in patients with DFU.

\section{Case Report}

A 67-year-old woman applied to our clinic in 2015 with complaints of left leg pain and unhealed purulent ulcers at the sole of her left foot, dizziness, frequent headaches and high blood pressure. She had been diagnosed to have DM for at least 8 years (the undiagnosed DM period is not known), DFU of neuropathic origin and had a medical decision for an above ankle amputation for her left leg.

Her history revealed that she had had a chemical exposition (the ingredients of which has not been identified) on her left leg and foot 25 years ago which caused bruising and healed and the ulcers have developed at the sole of the same foot in 2008. She had undergone multiple interventions including numerous debritments of the ulcers, phalanx and metatarsal amputations for osteomyelitis. Her left foot MRI unveiled amputation of the third phalanx together with the amputation of the 3rd metatarsal bone due to repeated osteomyelitis. She received different modes of treatments since then including immobilization and elevation of the leg, wet dressings, antibiotics and repeated debritment of the ulcerations.

On admission, she was on Metformin, Insulin Glargine, Fast Acting Insulin for the last 4 years for her DM and Amlodipine and Furosemide for her hypertension for 15 years. She has been on acetyl salycilic acid (ASA) therapy for antiaggregant therapeutic purposes.

Physical examination put forward edema over her left foot up to the ankle, skin color changes up to the calf region, absence of distal pulses beyond the knee, purulent, foul smelling ulceration measuring $3 \times 4 \mathrm{~cm}$ at the lateral sole of her left foot and a fistula orifice with purulent discharge at the plantar site of the 
1st finger (Figure 1).

Peripheral angiogram revealed diffuse peripheral arterial disease in her left lower extremity beyond the trifucation level (Figure 2). This has led us to re-diagnose the patient to have DFU with neuropathic and vascular components.

The most commonly used DFU classifications over the world is Meggit-Wagener and Amid Jain's classification [5]. With her findings, our patient was scored according to Megitt-Wagner classification to have a score of 3 (On a scale between 0 and 5).

All her antiaggregant and insulin therapies were ceased. She received i.v. major ozone application 2000 gamma/session 3 times a week for 2 weeks, external ozone sac application starting from 60 and dropping to 30 gamma/session for 3 weeks and ozone insuflation 40 gamma/session for 10 sessions. Her purulent discharge ceased after the third session and the the atonic debris of the wounds exfoliated thus wounds healed from the base towards the surface of the skin (Figure 3 and Figure 4).

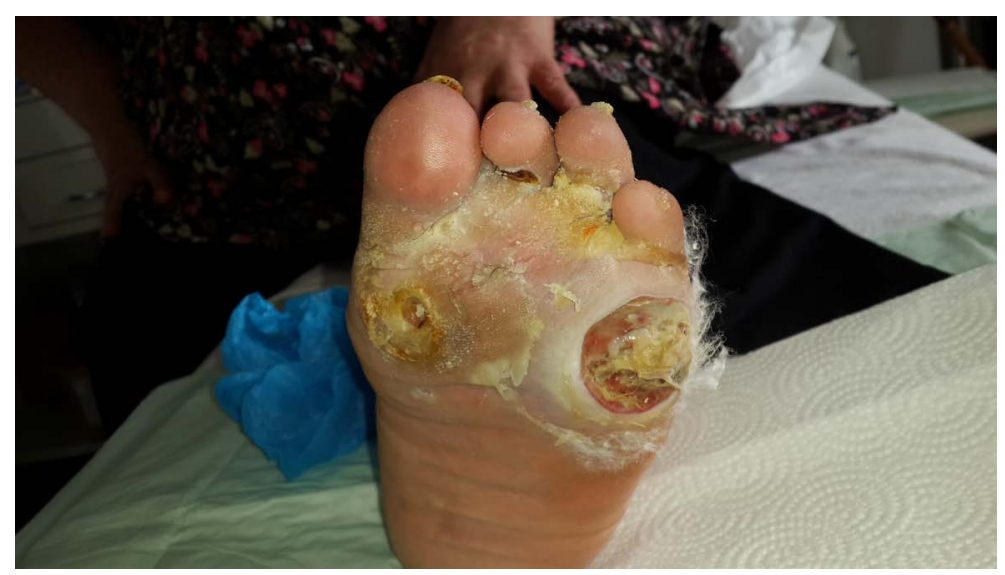

Figure 1. The appearance of the foot at presentation.

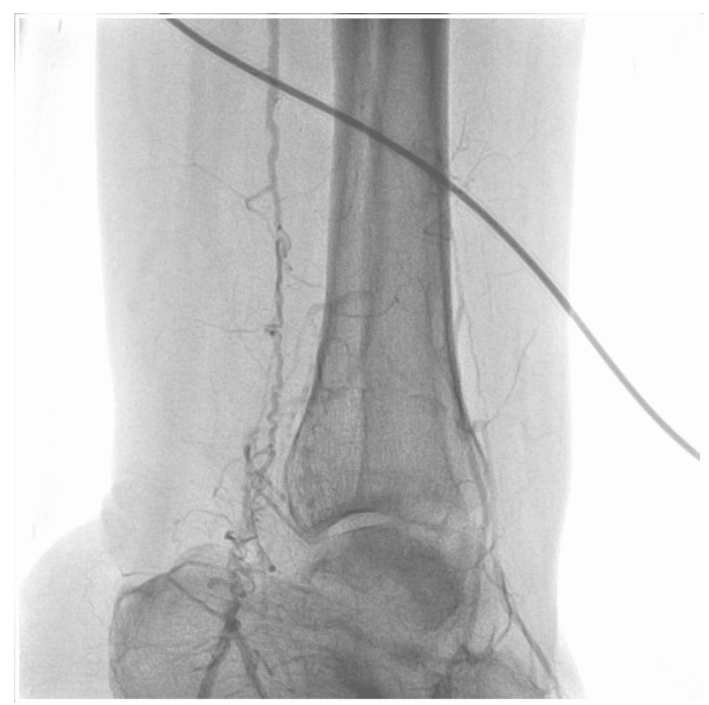

Figure 2. A photograph taken from the angiogram of the patient showing distal type peripheral arterial disease. 


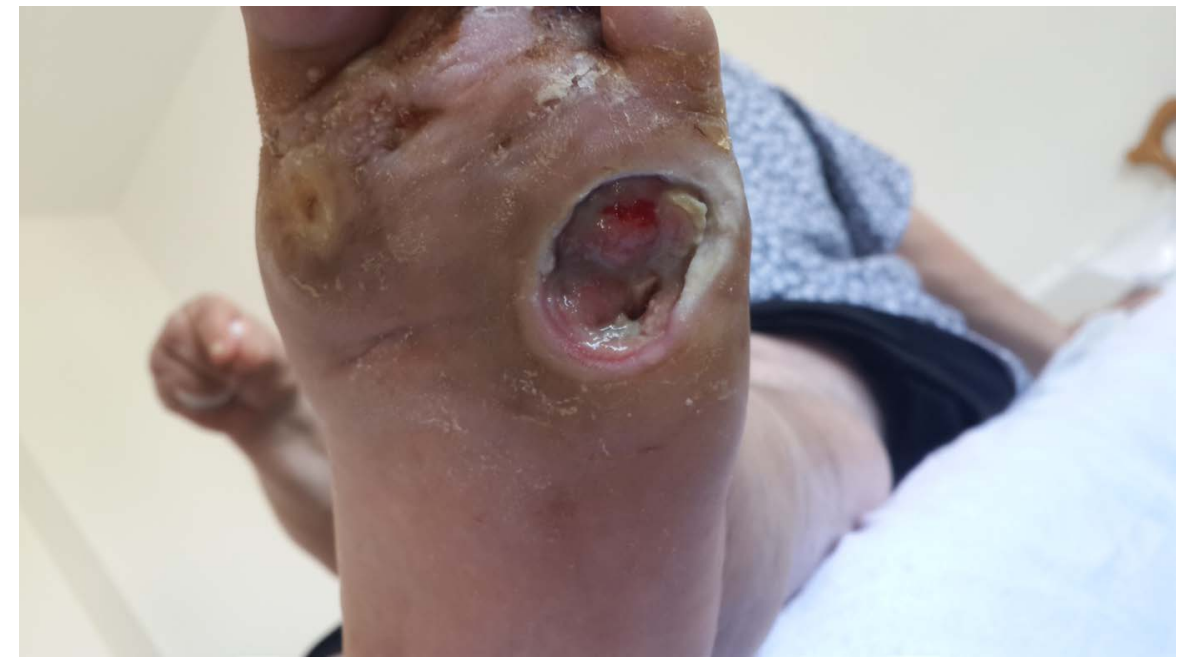

Figure 3. The appearance of the foot after the third application of ozone.

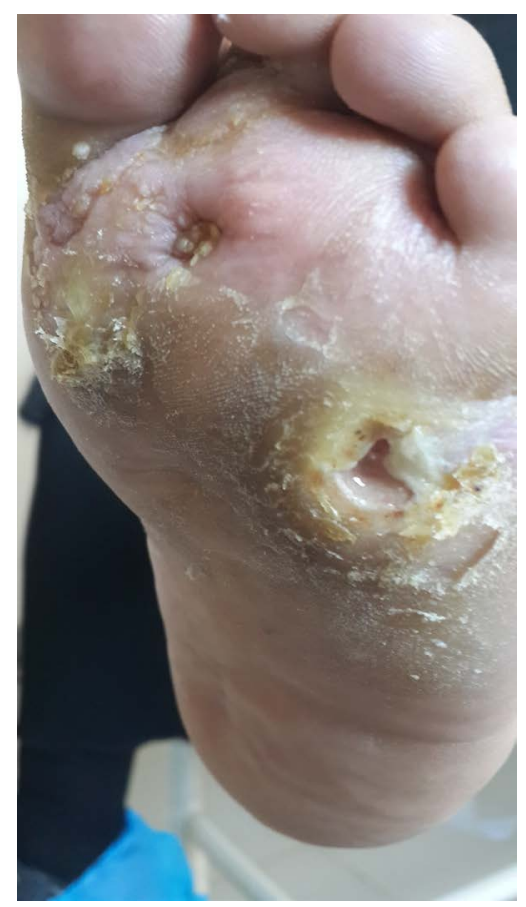

Figure 4. The appearance of the foot after one month.

Her blood glucose levels were followed 4 times/day and were found to be between $136-231 \mathrm{mg} / \mathrm{dl}$. Once her treatment was completed she carried out her treatment with her oral antidiabetic regimen without insulin and the addition of silostazol $100 \mathrm{mg}$. for two times a day and clopidogrel $75 \mathrm{mg}$. once a day, for a better circulation of the foot. The foot was almost fully healed after three months (Figure 5) after which the patient discontinued her visits. A phone feedback was received from the patient at October 2018 and she confirmed she still did not have her foot amputated and she is in good health with delicate self care, still without insulin. She also verbally confirmed on the telephone the publication of these findings without revealing her identity. 


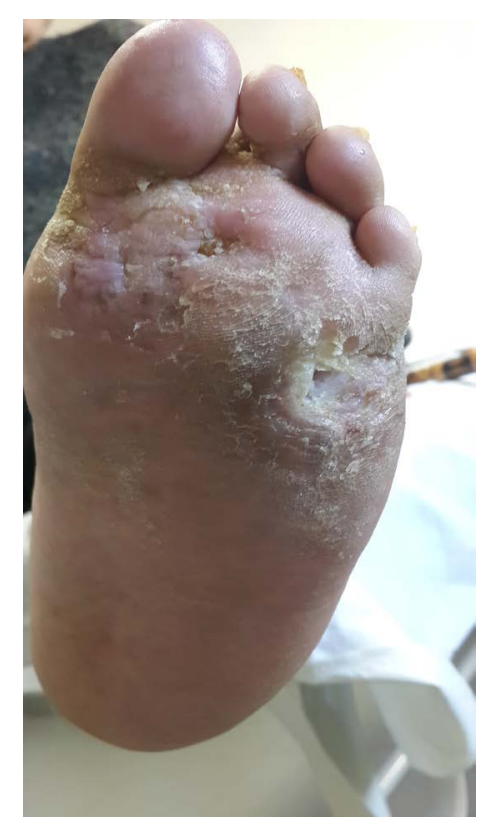

Figure 5. The final appearance of the foot.

\section{Discussion}

The DFU complication that occurs in 1 in 4 diabetic patients which leads to lengthened hospital inpatient stays and loss of work power together with loss of economic recourses as well as physical and psychological morbidities, usually requires a team work of vascular surgeons, plastic surgeons, endocrinologists, cardiologists, orthopedists and infectious diseases specialists for a basic comprehensive treatment of the DFUs [6].

The presence of deep wound infection, i.e. osteomyelitis in DFU is an independent risk factor for lower limb amputations [6] [7]. This case represents an extreme case among the DFU patients with multiple bone amputations performed and above ankle amputation decision had been taken.

Despite different modalities of treatment forwarded in the literature, ozone therapy stands to be a unique way of management for the DFU in different terms. Application of ozone creates an oxidative preconditioning which stimulates the endogenous antioxidant system by blocking the xanthine/xanthine oxidase pathway which is one of the major pathways for the production of reactive oxygen species (ROS) [8]. Blood glucose levels were shown to be regulated better with ozone application as insulin secretion is enhanced due to regulation of the compromised circulation and lowering glucose levels is one of the basic methods in the treatment in of DFU [8] [9]. Moreover, ozone is demonstrated to be a potent antibacterial agent very effective on different antibiotic resistant bacteria like Staphyloccus aureus, Acinetobacter baumannii, Enterococcus faecalis, Klebsiella pneumoniae and Pseudomonas aeruginosa [10].

Wound healing in DFU has been shown to be very much related with the presence of growth factors like vascular endothelial growth factor (VEGF), transforming growth factor beta (TGF- $\beta$ ) and platelet derived growth factor 
(PDGF) and local applications of growth factors have not put forward anticipated results [11]. It is therefore may be very important to stimulate the expressions of endogenous growth factors at local wound site for a better wound healing and ozone treatment appears to be promising in expressing the local growth factors much more effectively.

Randomized controlled trials are very rare with patients having DFU whom are treated with ozone therapies and there are only limited numbers of review reports citing these trials. In one review published in 2015 Liu et al. [12] have indicated to the insufficiency of the present trials to reach to a decision about the importance of ozone therapies in DFU patients. They concluded that in the short term, ulcer size could have been reduced more in DFU patients who received ozone as well as classical treatment when compared with patients who received classical methods of treatment only, however, they forwarded that the long term results were not witnessed in those trials with flaws in their designs therefore indicated to the need of new, strongly designed and well conducted randomized controlled trials with longer patient follow up. This propose on its own indicates to the importance of case reports on this topic for raising more knowledge. In this context our case turns out to be a good example for DFU management with ozone treatment also in terms of the cessation of classical medicines and applying ozone solely for the treatment and re-establishing her medicines in the light of the guidelines for peripheral arterial diseases and DFU.

On the other hand, a second review by Izadi et al. [13] forwarded that some studies combining ozone therapies (including ozonated water and oils for topical dressings) with standard treatment methods were compared with standard therapies alone where significant reduction in amputations and better ulcer healing was observed in the combined therapy group in comparison with the standard treatment group. Even this review denotes to the application to be a complementary approach while in our case it was the primary approach. In this context understanding the mechanisms of ozone's actions in the body would most probably open new horizons in the treatment of such patients [14]. Maybe, increased number of case reports will prepare a basis for the conduction of better designed randomized controlled studies in the future.

\section{Conclusion}

In conclusion, desperate DFU patients with neurogenic and/or vascular origin can be given an opportunity for a final treatment method with ozone before a decision for amputation; at least maybe, even it cannot salvage the extremity, a lower level amputation can be obtained for a better quality of life for such patients.

\section{Conflicts of Interest}

The authors declare no conflicts of interest regarding the publication of this paper. 


\section{References}

[1] Wild, S., Roglic, G., Green, A., Sicree, R. and King, H. (2004) Global Prevalence of Diabetes Estimates for the Year 2000 and Projections for 2030. Diabetes Care, 27, 1047-1053. https://doi.org/10.2337/diacare.27.5.1047

[2] Almobarak, A.O., Awadalla, H., Osman, M. and Ahmed, M.H. (2017) Prevalence of Diabetic Foot Ulceration and Associated Risk Factors: An Old and Still Major Public Health Problem in Khartoum, Sudan. Annals of Translational Medicine, 5, 340-346. https://doi.org/10.21037/atm.2017.07.01

[3] Zhang, P.Z., Lu, J., Jing, Y.L., Tang, S.Y.Y., Zhu, D.L. and Bi, Y. (2017) Global Epidemiology of Diabetic Foot Ulceration: A Systematic Review and Meta-Analysis. Annals of Medicine, 49, 106-116. https://doi.org/10.1080/07853890.2016.1231932

[4] van Asten, S.A.V., Mithani, M., Peters, E.J.G. and La Fontaine, J. Complications during the Treatment of Diabetic Foot Osteomyelitis. Diabetes Research and Clinical Practice. (Epub Ahead of Publication) https://doi.org/10.1016/j.diabres.2017.06.002

[5] Kushmakov, R., Gandhi, J., Seyam, O., Jiang, W., Joshi, G., Smith, N.L., et al. (2018) Ozone Therapy for Diabetic Foot. Medical Gas Research, 8, 111-115.

[6] Barwell, N.D., Devers, M.C., Kennon, B., Hopkinson, H.E., McDougall, C., Young, M.J., et al. (2017) Diabetic Foot Infection: Antibiotic Therapy and Good Practice Recommendations. International Journal of Clinical Practice. (Epub Ahead of Publication) https://doi.org/10.1111/ijcp.13006

[7] Pickwell, K., Siersma, V., Kars, M., Apelqvist, J., Bakker, K., Edmonds, M., et al. (2015) Predictors of Lower-Extremity Amputation in Patients with an Infected Diabetic Foot Ulcer. Diabetes Care, 38, 852-857. https://doi.org/10.2337/dc14-1598

[8] Martínez-Sánchez, G., Al-Dalain, S.M., Menéndez, S., Re, L., Giuliani, A., Candelario-Jalil, E., et al. (2005) Therapeutic Efficacy of Ozone in Patients with Diabetic Foot. European Journal of Pharmacology, 523, 151-161.

https://doi.org/10.1016/j.ejphar.2005.08.020

[9] Bocci, V., Zanardi, I., Huijberts, M.S.P. and Travagli, V. (2011) Diabetes and Chronic Oxidative Stress. A Perspective Based on the Possible Usefulness of Ozone Therapy. Diabetology \& Metabolic Syndrome, 5, 45-49.

[10] Fontes, B., Heimbecker, A.M.C., Brito, G.S., Costa, S.F., van der Heijden, I.M., Levin, A.S., et al. (2012) Effect of Low-Dose Gaseous Ozone on Pathogenic Bacteria. BMC Infectious Diseases, 12, 358-363. https://doi.org/10.1186/1471-2334-12-358

[11] Zhang, J., Guan, M.P., Xie, C.H., Luo, X.R., Zhang, Q. and Xue, Y.M. (2014) Increased Growth Factors Play a Role in Wound Healing Promoted by Noninvasive Oxygen-Ozone Therapy in Diabetic Patients with Foot Ulcers. Oxidative Medicine and Cellular Longevity, 2014, Article ID: 273475. https://doi.org/10.1155/2014/273475

[12] Liu, J., Zhang, P., Tian, J., Li, L., Li, J., Tian, J.H. and Yang, K.H. (2015) Ozone Therapy for Treating Foot Ulcers in People with Diabetes. Cochrane Database of Systematic Reviews, Article No. CD008474. https://doi.org/10.1002/14651858.CD008474.pub2

[13] Izadi, M., Jafari, N.J., Hosseini, M.S. and Saafaat, O. (2017) Therapeutic Effects of Ozone in Patients with Diabetic Foot Ulcers: Review of the Literature. Biomedical Research, 28, 7846-7850.

[14] Noel, L., Smith, N.L., Wilson, A.L., Gandhi, J., Vatsia, S. and Khan, S.A. (2017) Ozone Therapy: An Overview of Pharmacodynamics, Current Research, and Clinical Utility. Medical Gas Research, 7, 212-219. 